\title{
SCAN360: A Resource for a 360-Degree View of Cancer Prevention, Risk, and Survival
}

\author{
Zinzi Bailey, ScD, MSPH ${ }^{1,2}$; Raymond Balise, $\mathrm{PhD}^{1,3}$; Layla Bouzoubaa, $\mathrm{MPH}^{1}$; Erin Kobetz, PhD, MPH ${ }^{1,2}$
}

\begin{abstract}
Accessible Version: www.cdc.gov/pcd/issues/2020/20_0263.htm
Suggested citation for this article: Bailey Z, Balise R, Bouzoubaa L, Kobetz E. SCAN360: A Resource for a 360-Degree View of Cancer Prevention, Risk, and Survival. Prev Chronic Dis 2020;17:200263. DOI: https://doi.org/10.5888/pcd17.200263.
\end{abstract}

\section{PEER REVIEWED}

\section{Summary}

What is already known on this topic?

Understanding the patterns of cancer etiology, morbidity, and mortality across populations involves multiple levels of factors, ranging from the biological to the societal.

What is added by this report?

We describe the data sources, integration, calculations, and opportunities associated with SCAN360, an interactive web platform aiming to provide a "360-degree view" of factors that drive cancer burden in Florida, which can be replicated nationwide.

What are the implications for public health practice?

SCAN360 is an accessible resource for hospital administrators, community organizations, and public officials to make informed, comprehensive, and population-specific decisions.

\section{Abstract}

SCAN360, an interactive web platform aiming to provide a "360degree view" of factors that drive cancer, calculates and integrates several measures of cancer burden from the Florida Cancer Data System, the state's cancer registry, from 2012 to 2016 with cancer risk factors, clinical factors, and social determinants of health on multiple levels of geography - ranging from the entire state to the neighborhood. Integrating various sources of data, the web platform visualizes numerous indicators, including sociodemographic characteristics, cancer histology and staging, risk behaviors, screening behavior, environmental factors, hazardous sites, health insurance access, prevalence of potential comorbidities, housing characteristics, and levels of residential segregation, through maps and easy-to-interpret graphs. By walking through an example of a practical use, we show that SCAN360 provides data that are eas- ily accessible to public health professionals, decision makers, and researchers and can assist them with identifying potential drivers of cancer burden on a localized level.

\section{Background}

As the second leading cause of death in the United States, cancer is a major public health problem in communities across the nation $(1,2)$. Key behaviors (eg, smoking, heavy drinking, inactivity), infectious agents (eg, human papillomavirus [HPV], hepatitis B, hepatitis C, HIV, Helicobacter pylori), and genes (eg, BRCA1, $B R C A 2, p 53)$ increase the risk of developing cancer (2-4). However, cancer is complex, and understanding its pattern across populations involves an interplay between multiple levels of factors, ranging from the biological to the societal. This understanding must include recognition of the role of physical and social environments in shaping lifestyles, habits, health-promoting resources, and prevalence of infectious agents (2). Although some states have developed systems that integrate area-level measures of social and built environments and geocoded cancer registry data (eg, California Neighborhoods Data System [2]), Florida did not have this kind of integrated system before the development of SCAN360, an interactive web platform aiming to provide a "360degree view" of factors that drive cancer burden in Florida (5).

SCAN360 calculates and integrates several measures of cancer burden from the Florida Cancer Data System (FCDS), the state's cancer registry, with cancer risk factors, clinical factors, and social determinants of health on multiple levels of geography - ranging from the state to the neighborhood. SCAN360 shows choropleth maps with color schemes that draw attention to areas with high values. The web platform visualizes various indicators, including sociodemographic characteristics, cancer histology and staging, risk behaviors, screening behavior, environmental factors, hazardous sites, health insurance access, prevalence of potential comorbidities, housing characteristics, and levels of residential segregation, through maps and easy-to-interpret graphs. SCAN360 is a tool used by cancer centers in their cancer control strategies, but it is also an accessible resource for hospital administrators, community organizations, and public officials to make informed, com- 
prehensive, and population-specific decisions. This article describes the data sources, integration, calculations, and opportunities for research and public health practice associated with SCAN360, which can be replicated nationwide.

\section{Data Sources and Platform Development}

Sponsored by the University of Miami's Sylvester Comprehensive Cancer Center and the Miami Clinical and Translational Science Institute, SCAN360 provides tabular and graphical summaries, including interactive maps, for 19 types of cancer. It uses 4 measures: age-standardized 5-year incidence, mortality, prevalence of late-stage diagnosis, and the years of potential life lost attributable to cancer during 5 calendar years, 2012-2016. These statistics are available at many levels of aggregation, including 3 sex groups (male, female, everyone), 4 racial/ethnic groups (nonHispanic White, non-Hispanic Black, Hispanic, all races), 4 age groups (youth [0-19 y], adult [20-64 y], senior [ $\geq 65 \mathrm{y}]$, and everyone), and 5 levels of geography. The geographies - the entire state of Florida, all 67 Florida counties, 764 census-defined places (CDPs), and 11 Miami city districts - were selected to provide policy makers with meaningful locations.

Although cities, villages, and townships (what the Census calls CDPs) are critical to making policy decisions, the FCDS tags and reports cancer by census tract, not CDP. The US Census Bureau does not provide a direct mapping between census tracts and CDPs. Therefore, we used the MABLE GeoCorr 2014: Geographic Correspondence Engine, provided by the Missouri Census Data Center, to assign census tracts to CDPs (6). If a tract boundary crosses multiple CDPs, the cancer cases in that tract are assigned to the CDP with the largest population. This process avoids double counting, but it causes smaller places to be subsumed by neighboring, more populous CDPs. Therefore, SCAN360 reports on 764 of the 921 CDPs in Florida.

We standardized FCDS-provided data on incident cancer cases for 2012-2016 relative to the 2000 US Census. We calculated agestandardized mortality rates for the same by using data from the Florida Department of Health Bureau of Vital Statistics. We estimated both rates by using the direct standardization function in the epitools R package version 0.5-10.1 (R Foundation for Statistical Computing). We calculated years of potential life lost to cancer deaths by adapting the methodology for overall years of potential life lost to cancer deaths before age 65 instead of all deaths before age 65 (7). Because of restrictions imposed by the FCDS, the SCAN360 website does not display any cancer incidence or mortality rates for any geography that has fewer than 10 cases of cancer. We calculated other cancer statistics, such as the percentage of people diagnosed at a late stage (SEER [Surveillance, Epidemiology, and End Results] Summary stages 2 through 7) and the frequency of the histological variants (by cancer and race/ethnicity) by using functions from the tidyverse R package version 1.2.1 (8).

In addition to cancer statistics, SCAN360 offers summaries of relevant behavioral and environmental risk factors, including data on 18 unique factors known to influence cancer incidence and mortality, available through the American Community Survey (9). These factors include average commute time, access to a vehicle, insurance status, and 10 cancer risk and protective factors captured in the 2016 Behavioral Risk Factor Surveillance System (BRFSS), such as mammography and colorectal cancer screening. In choosing which risk and protective factors are the most relevant to the cancers included in SCAN360, the research team conducted literature reviews of sociodemographic, environmental, behavioral, clinical, and other risk factors, and sought advice from experts in the fields of cancer epidemiology, medical oncology, social epidemiology, and health disparities. We sourced data on environmental factors, such as the presence of toxins in the air, the amount of ultraviolet exposure, the air quality index, and the prevalence of food insecurity, from federal agencies such as the Environmental Protection Agency and the Centers for Disease Control and Prevention (Tables 1 and 2). This information is available on the SCAN360 website (scan360.com) (5).

We conducted all analyses for SCAN360 using R 3.5.3 software (R Foundation for Statistical Software). We extracted American Community Survey data for various geographies via API (application programming interface) calls using the acs $\mathrm{R}$ package version 2.1.4 (R Foundation for Statistical Computing); that is, we used the $\mathrm{R}$ programming language to communicate with the US Census Bureau without human intervention, and we calculated percentages for each level of geography using the base $\mathrm{R}$ and tidyverse functions. We defined Miami city districts by their census tracts. For each district, we calculated factor estimates by taking the average of that estimate weighted by the population in the census tract. Because BRFSS data are available only at the county level, we calculated rates of behavior (eg, mammography screening) for CDPs and districts from census tract-level data obtained from the 500 Cities Project (10).

SCAN360 enables the comparison of 2 rates for any cancer or contextual factor (behavioral/environmental/socioeconomic) for any combination of geography and population subgroup through side-by-side maps. We obtained the shapefiles used to draw the maps for the state, counties, and CDPs from the tigris $\mathrm{R}$ package version 0.8.2 ( $\mathrm{R}$ Foundation for Statistical Computing). We created a shapefile for Miami city districts by grouping the census tracts that define them and spatially joining them using ArcMap version 10.6 software (Esri).

The opinions expressed by authors contributing to this journal do not necessarily reflect the opinions of the U.S. Department of Health and Human Services, the Public Health Service, the Centers for Disease Control and Prevention, or the authors' affiliated institutions. 


\section{Use of SCAN360 to Explore Cancer Incidence in Florida}

SCAN360 combines several measures of cancer burden into a single user-friendly platform (Figure 1). The higher rates in central and northern Florida in overall cancer incidence and mortality shown on the SCAN360 maps is consistent with rural health disparities and proximity to the Deep South (https://bit.ly/overallcancer) $(11,12)$. However, when focusing on cancer control and prevention, it is important to recognize that some cancers disproportionately contribute to the cancer burden in some geographic areas. For example, in South Florida, the 4-county region of MiamiDade, Broward, Palm Beach, and Monroe counties, is a sociodemographically heterogeneous area that accounts for nearly $30 \%$ of the population in Florida. Through SCAN360, this heterogeneity can be explored in relationship to drivers and correlates of cancer burden.

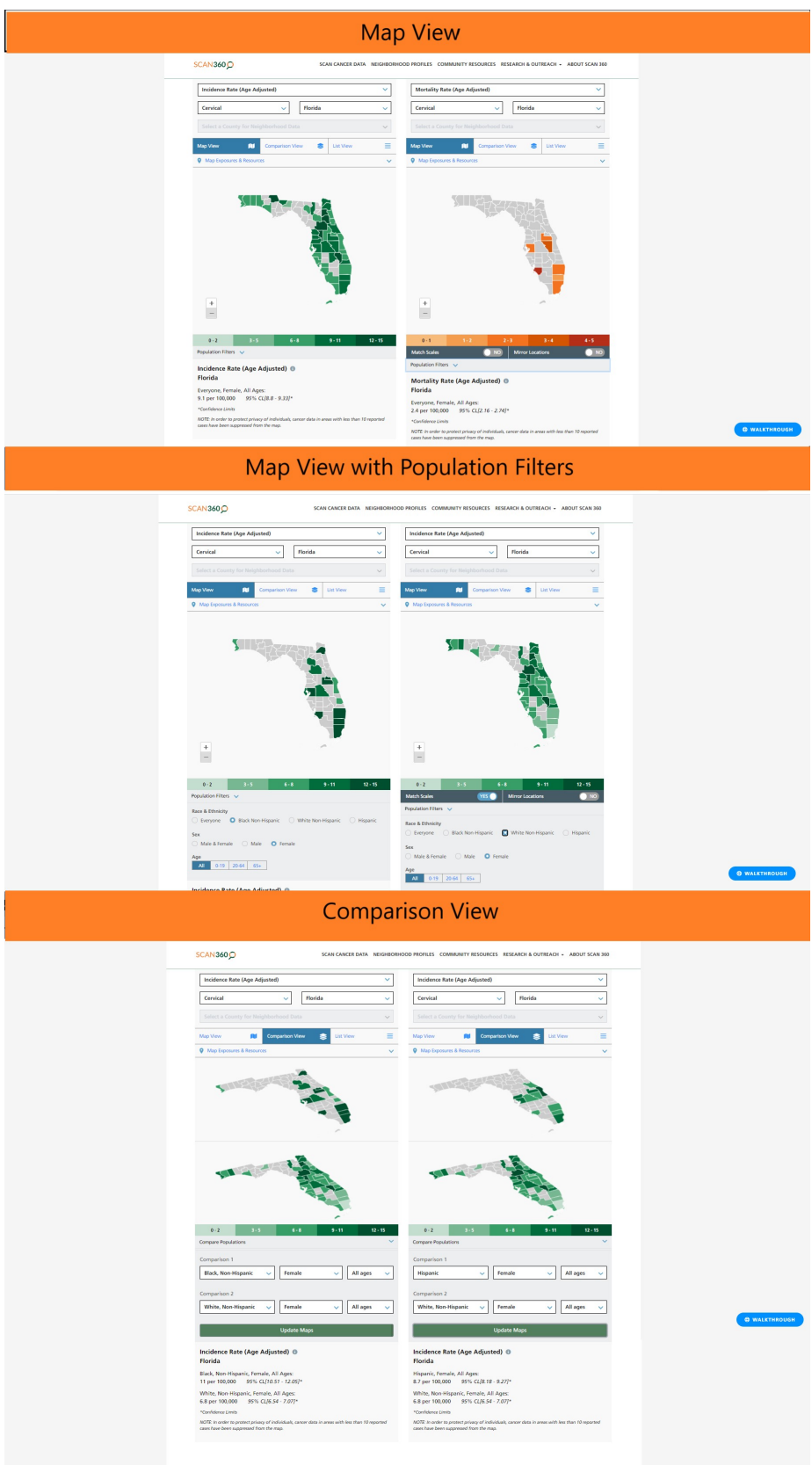

Figure 1. Map view, map view with population filters, and comparison view in SCAN360.

The incidence rates of cervical cancer in Miami-Dade, Broward, and Monroe counties stand out from neighboring counties (https:// bit.ly/cervicalcancerFL). Furthermore, when exploring the population filters in SCAN360, cervical cancer in Miami-Dade County stands out at older ages, especially among women aged 65 or older, which can be seen in SCAN360 by using the hover feature

The opinions expressed by authors contributing to this journal do not necessarily reflect the opinions of the U.S. Department of Health and Human Services, the Public Health Service, the Centers for Disease Control and Prevention, or the authors' affiliated institutions. 
over Miami-Dade County (https://bit.ly/agepopfilter). The estimated age-adjusted cervical cancer incidence rate among women aged 20 to 64 in Miami-Dade County is 14 per 100,000 (with a $95 \%$ CI that includes the statewide rate for the same age group), whereas the rate for women aged 65 or older in Miami-Dade County is 17 per 100,000 (vs 11 per 100,000 statewide in the same age group). The higher rate among older women likely reflects many factors, including geographic distribution of people across different ages, which can be investigated through further population filters. For example, we can also look at cervical cancer across race and ethnicity. When the population filters are used to focus on non-Hispanic Black women, Miami-Dade, Broward, and Palm Beach counties stand out among other counties in Florida as having the highest rates of cervical cancer ( 13 per 100,000; 14 per 100,000; and 13 per 100,000; respectively). To a lesser degree, we see the same counties in this catchment area stand out with high rates among Hispanic women (Miami-Dade, 9.3 per 100,000; Broward, 7.8 per 100,000; and Palm Beach, 6.6 per 100,000) compared to the rates in other counties (side-by-side maps available at https://bit.ly/SCANblackhispanic).

The high rates among non-Hispanic Black and Hispanic women in the catchment area are distinctive, especially when compared with the pattern of incidence among non-Hispanic White women in the same counties (https://bit.ly/SCANwhiteblack). Again, this racial/ ethnic difference in the geographic distribution of cancer incidence is likely to reflect many factors, including the underlying distribution of racial/ethnic groups (with different age distributions) across different geographies, which can be more thoroughly investigated through further study. However, looking at the magnitude and precision of the disparity in incidence, we can infer that the incidence of cervical cancer in Miami-Dade, Broward, and Palm Beach counties is concentrated among Black (and to a lesser extent, Hispanic) women in South Florida.

We can look at these data in another way, through the comparison view, which magnifies the ability to display contrasts in incidence rates by geography and population (https://bit.ly/SCANCom$\mathrm{pView}$ ). Although contextualizing incidence rates in the broader landscape of Florida is helpful, documenting and visualizing disparities at the county level is not sufficient to guide targeted outreach and research. We must look more closely at the heterogeneity within each county. Zooming into Miami-Dade County in Map View, we get a sense of geographic heterogeneity (https:// bit.ly/SCAN305). Choosing a county allows the user to select even smaller levels of geography — neighborhoods.

Zooming in to the neighborhood level, we see that neighborhoods such as Little Haiti, North Miami, Model City, West Little River, Golden Glades, Homestead, Leisure City, and University Park have the highest rates of cervical cancer in the county. Further- more, if we restrict our investigation of cervical cancer incidence to non-Hispanic Black women, we observe the highest rates in Miami Gardens (16 per 100,000), Little Haiti (20 per 100,000), and North Miami (23 per 100,000) (https://bit.ly/SCANMIABH). If we restrict our investigation of cervical cancer incidence to Hispanic women, we see different neighborhoods stand out, including Hialeah, Allapatah, Little Havana, Miami Beach, and Homestead, not surprisingly predominantly Hispanic/Latinx communities (https://bit.ly/SCANMIABH).

SCAN360 also provides data about each neighborhood, allowing comparisons of environment (eg, housing stock, rent burden, housing vacancy), sociodemographic composition (eg, race/ethnicity, education, income), and resources (eg, health care access, concentration of poverty) across neighborhoods. If we compare Little Haiti with the City of Miami (the urban center of Miami-Dade County), we see that $70 \%$ of residents in Little Haiti have an extreme rent burden, meaning that more than $50 \%$ of their income is spent on housing (https://bit.ly/SCANLittleHaitivMiami). Furthermore, we see more housing vacancy and less housing dedicated to "occasional use" (ie, vacation homes). This snapshot of data may reflect secular changes occurring to a greater extent in Little Haiti than in the City of Miami overall. The resources and social support in Little Haiti may be disrupted by sociodemographic and environmental changes in the neighborhood caused by gentrification and displacement, and affect cancer risk, treatment, and survival. In addition to providing information on risk and protective factors, SCAN360 affords the opportunity to delve into detailed cancer statistics, including age at diagnosis, histology, percentage of latestage diagnosis, and protective resources and detrimental exposures in the community (Figure 2).

The opinions expressed by authors contributing to this journal do not necessarily reflect the opinions of the U.S. Department of Health and Human Services, the Public Health Service, the Centers for Disease Control and Prevention, or the authors' affiliated institutions. 


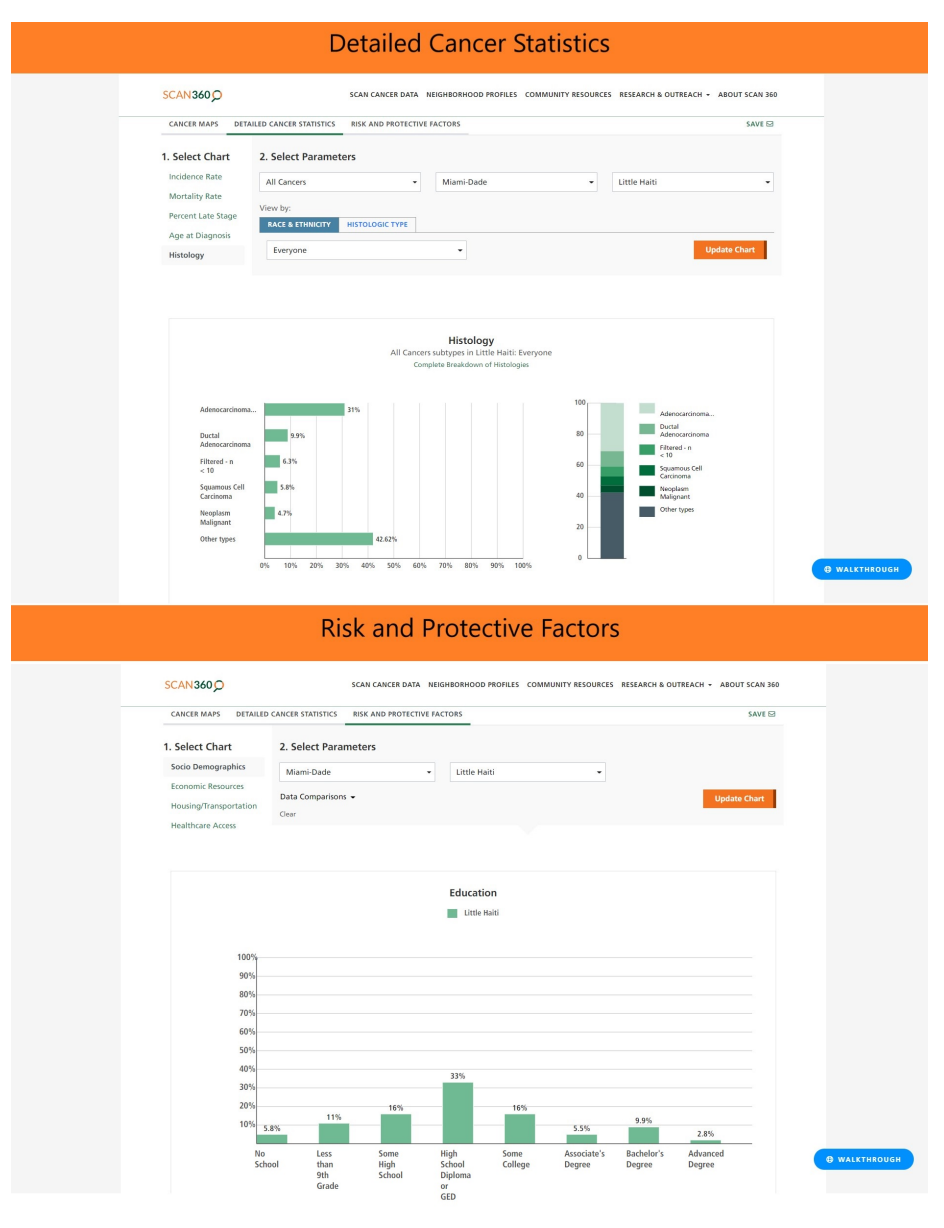

Figure 2. Visualizing exposures and resources using SCAN360.

In addition, the side-by-side choropleth maps allow comparison not just of different populations; this display allows for the comparison of cancer outcomes with a range of economic, environmental, health behavior, housing, transportation, sociodemographic, and other health characteristics. For instance, zooming in to Golden Glades, North Miami, and West Little River, we can see that many neighborhoods with the highest incidence rates of cervical cancer among Black women are also among the neighborhoods with the lowest levels of median income (https://bit.ly/ CervIncome) and health insurance access among women aged 18 to 64 (https://bit.ly/CervicalInsur).

The correlational relationships suggested by the side-by-side maps can spark new research, and we advocate use of the maps primarily for generating hypotheses, to avoid ecological fallacy. Hypothesis generation allows for further innovative investigation through a range of analyses (eg, multilevel, spatial regression). For example, catalyzed by hypothesis generation using basic residential segregation data, ovarian cancer data, and visualizations from SCAN360, researchers conducted an in-depth analysis of the effect of residential segregation on epithelial ovarian cancer survival in Florida by race/ethnicity (13).

\section{Public Health Implications}

Recognizing the multiple levels of interplay in the patterning of health and health inequities, we can use SCAN360 to help identify key geographic areas in which to concentrate resources, build relationships with local community partners, and develop community-tailored policies and programs not only to mitigate cancer burden but also to reduce disparities in cancer. In short, SCAN360 provides a platform and resources to analyze the potential causal interplay between biological, behavioral, social, and structural factors across populations and geographic areas, and, therefore, can help guide cancer control and prevention efforts. For cancer centers in Florida, SCAN360 can help highlight areas of investigation and outreach that are particularly relevant to their catchment areas. Combining cancer registry data with comprehensive data sources allows for directed multilevel research in Florida, a state characterized by cultural heterogeneity. Some areas in North and Central Florida are culturally, demographically, and historically similar to the Deep South, whereas South Florida has multiple enclaves of immigrant residents. The burden of cervical cancer is a particular concern for communities in South Florida, given the concentration of immigrant populations with limited access to human papillomavirus (HPV) vaccination in their countries of birth and their current communities and limited access to methods of secondary prevention (eg, cervical cancer screening, HPV co-testing). Other disease sites or features may be relevant for other cancer centers in the state, allowing each to allocate resources accordingly. In addition, SCAN360 sets the stage for multilevel research. For example, the frailty survival model uses both person-level and neighborhood-level factors to predict a woman's hazard of death from ovarian cancer (14) using data exported from SCAN360 (an option that should soon easily be accessible on our platform).

All data summarized on SCAN360 are updated annually as soon as the data become available. We plan to make SCAN360 a more comprehensive platform by including diseases and conditions such as HIV and stroke. As the data for these diseases and conditions become available, we will add data on risk and protective factors. The addition of these data may lead to more frequent updates.

We are exploring other ways to enhance the capabilities of the SCAN360 platform, including the addition of basic correlational statistics by geography, bivariate choropleth maps (to display the

The opinions expressed by authors contributing to this journal do not necessarily reflect the opinions of the U.S. Department of Health and Human Services, the Public Health Service, the Centers for Disease Control and Prevention, or the authors' affiliated institutions. 
relationship between 2 categorical variables on the same plot), user-defined neighborhoods/geographic regions, and survival data; expansion into other geographic areas (including New York), and incorporation of social media machine learning into community profiles. As of this writing, in September 2020, SCAN360 shows choropleth maps with color schemes that draw attention to areas with high values. Public health experts know to temper concerns for these highlighted areas if they see wide confidence intervals (which SCAN360 provides on mouse-click or hover-over). We are experimenting with value-suppressing uncertainty palettes, which fade the saturation of the choropleth map toward gray as a function of the width of confidence intervals (15). These maps will help focus attention on problem areas that are relatively certain. Researchers who wish to use the data in SCAN360 can request a data export. We are currently building self-service export tools that will provide analysis-ready data sets to support focused research.

SCAN360 and similar web platforms can provide an accessible way for decision makers, health care professionals, researchers, and community leaders to integrate and visualize comprehensive data across various levels of geography and across groups of race/ ethnicity, age, and sex/gender. This increased capacity can promote data-driven decision making and resource allocation, putting surveillance into action.

\section{Acknowledgments}

The development of SCAN360 was funded by the University of Miami's Sylvester Comprehensive Cancer Center, as well as by the National Center for Advancing Translational Sciences, National Institutes of Health, through the Miami Clinical and Translational Science Institute Grant Number UL1 TR002736. Its contents are solely the responsibility of the authors and do not necessarily represent the official views of the NIH. SCAN360 is protected by US Provisional Patent Application No. 62/751,299. The authors have no conflicts of interest to disclose.

\section{Author Information}

Corresponding Author: Erin Kobetz, PhD, MPH, University of Miami Miller School of Medicine, 1120 NW 14 St, Miami, FL 33136 . Te le phone: $305-243-8345$. Email: EKobetz@med.miami.edu.

Author Affiliations: 'Sylvester Comprehensive Cancer Center, University of Miami Miller School of Medicine, Miami, Florida. ${ }^{2}$ Division of Medical Oncology, Department of Medicine, University of Miami Miller School of Medicine, Miami, Florida.
${ }^{3}$ Division of Biostatistics, Department of Public Health Sciences, University of Miami, Miami, Florida.

\section{References}

1. Siegel RL, Miller KD, Jemal A. Cancer statistics, 2019. CA Cancer J Clin 2019;69(1):7-34.

2. Gomez SL, Shariff-Marco S, DeRouen M, Keegan TH, Yen IH, Mujahid M, et al. The impact of neighborhood social and built environment factors across the cancer continuum: current research, methodological considerations, and future directions. Cancer 2015;121(14):2314-30.

3. National Academies of Sciences, Engineering, and Medicine. Complexity: from cells to society. In: Johns MME, Madhavan G, Amankwah FK, Nass SJ, eds. Guiding cancer control: a path to transformation. Washington (DC): National Academies Press; 2019.

4. Lynch SM, Rebbeck TR. Bridging the gap between biologic, individual, and macroenvironmental factors in cancer: a multilevel approach. Cancer Epidemiol Biomarkers Prev 2013; 22(4):485-95.

5. Sylvester Comprehensive Cancer Center. SCAN 360. Home. http://www.scan360.com. 2018. Accessed December 20, 2018.

6. Missouri Census Data Center, University of Missouri Center for Health Policy. Geocorr 2014: geographic correspondence engine. http://mcdc.missouri.edu/applications/ geocorr2014.html. Published 2016. Updated September 10, 2016. Accessed January 1, 2019.

7. US Department of Health and Human Services, Centers for Disease Control and Prevention. Lesson three: measures of risk. Section 3: mortality frequency measures. U.S. Department of Health and Human Services, Centers for Disease Control and Prevention. Principles of epidemiology in public health practice: an introduction to applied epidemiology and biostatistics. https://www.cdc.gov/csels/dsepd/ss1978/lesson3/ section3.html. Published 2006. Accessed October 6, 2020.

8. Wickham H, Averick M, Bryan J, Chang W, McGowan L, François R, et al. Welcome to the Tidyverse. J Open Source Softw 2019;4(43):1686.

9. US Census Bureau. American Community Survey. https:// www.census.gov/programs-surveys/acs. Accessed November 9, 2020.

10. Centers for Disease Control and Prevention, National Center for Chronic Disease Prevention and Health Promotion, Division of Population Health. 500 Cities Project, 2018release. https:/chronicdata.cdc.gov/500-Cities/500-Cities-Local-Datafor-Better-Health-2018-relea/6vp6-wxuq. Accessed December $15,2018$.

\footnotetext{
The opinions expressed by authors contributing to this journal do not necessarily reflect the opinions of the U.S. Department of Health and Human Services, the Public Health Service, the Centers for Disease Control and Prevention, or the authors' affiliated institutions.
} 
11. Singh GK, Williams SD, Siahpush M, Mulhollen A. Socioeconomic, rural-urban, and racial inequalities in US cancer mortality: Part I - All cancers and lung cancer and Part II - Colorectal, prostate, breast, and cervical cancers. J Cancer Epidemiol 2011;2011:107497.

12. Zahnd WE, James AS, Jenkins WD, Izadi SR, Fogleman AJ, Steward DE, et al. Rural-urban differences in cancer incidence and trends in the United States. Cancer Epidemiol Biomarkers Prev 2018;27(11):1265-74.

13. Westrick AC, Bailey ZD, Schlumbrecht M, Hlaing WM, Kobetz EE, Feaster DJ, et al. Residential segregation and overall survival of women with epithelial ovarian cancer. Cancer 2020;126(16):3698-707.

14. Westrick A, Schlumbrecht M, Hlaing WM, Kobetz EK, Feaster D, Balise R. Racial and ethnic disparities in the overall survival of women with epithelial ovarian cancer in Florida, 2001-2015. Cancer Causes Control 2020;31(4):333-40.

15. Correll M, Moritz D, Heer J. Value-suppressing uncertainty palettes. Proceedings of the $2018 \mathrm{CHI}$ Conference on Human Factors in Computing Systems. Paper no. 642. 2018Apr 21-26; Montreal, Canada.

The opinions expressed by authors contributing to this journal do not necessarily reflect the opinions of the U.S. Department of Health and Human Services, the Public Health Service, the Centers for Disease Control and Prevention, or the authors' affiliated institutions. 


\section{Tables}

Table 1. American Community Survey Tables ${ }^{a}$ and Associated Neighborhood Package Functions With Levels Used in SCAN360

\begin{tabular}{|c|c|c|c|}
\hline Table Name & $\begin{array}{l}\text { American Community Survey } \\
\text { Table No. }\end{array}$ & Package Function & Levels \\
\hline Sex by age & B01001 & plot_age & $\begin{array}{l}\text { 5-year age groups by sex: } 0-4 / 5-9 / 10-14 / 15-19 / \ldots / 75-79 / \\
80-84 / \geq 85\end{array}$ \\
\hline Travel time to work & B08303 & plot_commute & $\geq 90 /<90 /<60 /<45 /<30 /<15 \min$ \\
\hline $\begin{array}{l}\text { Educational } \\
\text { attainment }\end{array}$ & B15003 & plot_education & $\begin{array}{l}\text { Advanced degree/bachelor's degree/ associate's degree/some college/ } \\
\text { high school diploma or GED/some high school/<9th grade/no school }\end{array}$ \\
\hline $\begin{array}{l}\text { Language spoken at } \\
\text { home }\end{array}$ & B16001 & plot_english & Speak other than English/speak only English \\
\hline $\begin{array}{l}\text { Hispanic or Latino } \\
\text { origin }\end{array}$ & B03003 & plot_ethnicity & Hispanic or Latino/not Hispanic or Latino \\
\hline $\begin{array}{l}\text { Median household } \\
\text { income in the past } 12 \\
\text { months }\end{array}$ & B19013 & plot_income & Actual median shown (no levels) \\
\hline $\begin{array}{l}\text { Health insurance } \\
\text { coverage by sex and } \\
\text { age }\end{array}$ & B27001 & plot_insurance & $\begin{array}{l}\text { By sex: male/female; by age: youth }(0-17 \text { y)/adult }(18-64 \text { y)/senior } \\
(\geq 65 \text { y) }\end{array}$ \\
\hline $\begin{array}{l}\text { Health insurance } \\
\text { coverage by sex, age, } \\
\text { and type }\end{array}$ & B27012 & plot_insurance_type & $\begin{array}{l}\text { By sex: male/female; by age: youth }(0-17 \text { y)/adult (18-64 y)/ } \\
\text { senior }(\geq 65 \text { y); by type: employer-based/Medicaid/Medicare/private }\end{array}$ \\
\hline Nativity & B05012 & plot_native & Foreign-born/native \\
\hline $\begin{array}{l}\text { Percentage of } \\
\text { population aged }>65\end{array}$ & B01001 & plot_over65 & Actual percentage shown (no levels) \\
\hline $\begin{array}{l}\text { Total population in } \\
\text { occupied housing } \\
\text { units by tenure }\end{array}$ & B25008_002/B25008_003 ${ }^{\mathrm{b}}$ & plot_own_rent & Rent/own \\
\hline $\begin{array}{l}\text { Ratio of income to } \\
\text { poverty level }\end{array}$ & C17002 & plot_poverty & $\begin{array}{l}>2 \text { times poverty threshold/ }<2 \text { times poverty threshold/ }<\text { poverty } \\
\text { threshold }\end{array}$ \\
\hline Race & B02001 & plot_race & $\geq 2$ Races/Pacific Islander/Asian/Native American/Black/White \\
\hline \begin{tabular}{|l} 
Gross rent as a \\
percentage of \\
household income
\end{tabular} & B25070 & plot_rentincome & Extreme rent burden $(>30 \%) /$ rent burden $<30 \%$ \\
\hline Employment status & B23025 & plot_unemployment & Unemployed/employed \\
\hline Vacancy status & B25004 & plot_vacancy & $\begin{array}{l}\text { Other vacant/for migrant workers/occasional use/sold, not occupied/ } \\
\text { for sale only/rented, not occupied/for rent }\end{array}$ \\
\hline \begin{tabular}{|l|} 
Means of \\
transportation to work \\
by vehicles available
\end{tabular} & B08141 & plot_vehicle & $\geq 1$ Vehicle/no vehicle \\
\hline Year structure built & B25034 & plot_year_built & $\begin{array}{l}1939 \text { or earlier/1940-1949/1950-1959/1960-1969/1970-1979/ } \\
1980-1989 / 1990-1999 / 2000-2009 / 2010-2013 / 2014 \text { or later }\end{array}$ \\
\hline
\end{tabular}

${ }^{\text {a }}$ US Census Bureau (9).

${ }^{\mathrm{b}}$ Data for this factor were obtained from 2 separate variables from the same table.

The opinions expressed by authors contributing to this journal do not necessarily reflect the opinions of the U.S. Department of Health and Human Services, the Public Health Service, the Centers for Disease Control and Prevention, or the authors' affiliated institutions. 
Table 2. Indicators and Data Sources Used in SCAN360

\begin{tabular}{|c|c|c|c|c|}
\hline Indicator & Source & Year & Type & URL \\
\hline Superfund sites & $\begin{array}{l}\text { Environmental Protection } \\
\text { Agency }\end{array}$ & 2018 & $\begin{array}{l}\text { Geocoded } \\
\text { addresses }\end{array}$ & https://www.epa.gov/superfund/national-priorities-list-npl-sites-state\#FL \\
\hline Nuclear power plants & Nuclear Energy Institute & 2018 & $\begin{array}{l}\text { Geocoded } \\
\text { addresses }\end{array}$ & $\begin{array}{l}\text { https://www.nei.org/CorporateSite/media/filefolder/resources/fact- } \\
\text { sheets/state-fact-sheets/Florida-State-Fact-Sheet.pdf }\end{array}$ \\
\hline Ultraviolet exposure & National Cancer Institute & 2017 & Rate & https://gis.cancer.gov/tools/uv-exposure \\
\hline Radon exposure & $\begin{array}{l}\text { Environmental Protection } \\
\text { Agency }\end{array}$ & 2017 & Index & $\begin{array}{l}\text { http://www.epa.gov/radon/zonemap.html; http://www.city-data.com/ } \\
\text { radon-zones/Florida/Florida.html }\end{array}$ \\
\hline $\begin{array}{l}\text { Limited access to healthy } \\
\text { food }\end{array}$ & $\begin{array}{l}\text { Robert Wood Johnson } \\
\text { Foundation (RWJF) County } \\
\text { Health Rankings; US } \\
\text { Department of Agriculture } \\
\text { (USDA) Food Environment Atlas }\end{array}$ & 2015 & Rate & http://www.countyhealthrankings.org/rankings/data/FL \\
\hline Food insecurity & $\begin{array}{l}\text { RWJF County Health Rankings; } \\
\text { Map the Meal Gap from } \\
\text { Feeding America }\end{array}$ & 2015 & Rate & http://www.countyhealthrankings.org/rankings/data/FL \\
\hline Food environment index & $\begin{array}{l}\text { RWJF County Health Rankings; } \\
\text { USDA Food Environment Atlas; } \\
\text { Map the Meal Gap from } \\
\text { Feeding America }\end{array}$ & 2015 & Index & http://www.countyhealthrankings.org/rankings/data/FL \\
\hline Exercise opportunities & $\begin{array}{l}\text { RWJF County Health Rankings; } \\
\text { Business Analyst; Delorme map } \\
\text { data; ESRI; US Census Tigerline } \\
\text { Files }\end{array}$ & 2016 & Rate & http://www.countyhealthrankings.org/rankings/data/FL \\
\hline $\begin{array}{l}\text { Percentage of population } \\
\text { living within } 0.5 \text { mile of a } \\
\text { park }\end{array}$ & $\begin{array}{l}\text { Centers for Disease Control } \\
\text { and Prevention (CDC) National } \\
\text { Environmental Public Health } \\
\text { Tracking Network }\end{array}$ & 2011 & Rates & https://ephtracking.cdc.gov/DataExplorer/\# \\
\hline Air quality index & $\begin{array}{l}\text { Environmental Protection } \\
\text { Agency }\end{array}$ & 2018 & Index & https://aqs.epa.gov/aqsweb/airdata/annual_aqi_by_county_2018.zip \\
\hline \begin{tabular}{|l|} 
Percentage of population \\
within $150 \mathrm{~m}$ of highway
\end{tabular} & $\begin{array}{l}\text { CDC National Environmental } \\
\text { Public Health Tracking Network }\end{array}$ & 2010 & Rate & https://ephtracking.cdc.gov/DataExplorer/\# \\
\hline $\begin{array}{l}\text { Percentage of public } \\
\text { schools within } 150 \mathrm{~m} \text { of } \\
\text { highway }\end{array}$ & $\begin{array}{l}\text { CDC National Environmental } \\
\text { Public Health Tracking Network }\end{array}$ & 2010 & Rate & https://ephtracking.cdc.gov/DataExplorer/\# \\
\hline Drinking water violations & $\begin{array}{l}\text { RWJF County Health Rankings; } \\
\text { Safe Drinking Water } \\
\text { Information System }\end{array}$ & 2016 & Binary & http://www.countyhealthrankings.org/rankings/data/FL \\
\hline $\begin{array}{l}\text { Percentage of severe } \\
\text { housing problems }\end{array}$ & $\begin{array}{l}\text { RWJF County Health Rankings; } \\
\text { Comprehensive Housing } \\
\text { Affordability Strategy (CHAS) } \\
\text { data }\end{array}$ & $2010-2014$ & Rate & http://www.countyhealthrankings.org/rankings/data/FL \\
\hline Residential segregation & $\begin{array}{l}\text { RWJF County Health Rankings; } \\
\text { American Community Survey, } \\
\text { 5-year estimates }\end{array}$ & $2012-2016$ & Index & http://www.countyhealthrankings.org/rankings/data/FL \\
\hline Income inequality & $\begin{array}{l}\text { RWJF County Health Rankings; } \\
\text { American Community Survey, } \\
\text { 5-year estimates }\end{array}$ & $2012-2016$ & Ratio & http://www.countyhealthrankings.org/rankings/data/FL \\
\hline $\begin{array}{l}\text { Supplemental Nutrition } \\
\text { Assistance Program } \\
\text { (SNAP) redemptions/ } \\
\text { SNAP-authorized stores }\end{array}$ & USDA Food Environment Atlas & 2018 & $\begin{array}{l}\text { Average } \\
\text { dollar }\end{array}$ & $\begin{array}{l}\text { https://www.ers.usda.gov/webdocs/DataFiles/48731/ } \\
\text { DataDownload.xls? }=0\end{array}$ \\
\hline Brownfields & $\begin{array}{l}\text { Florida Geographic Data Library } \\
\text { Metadata Explorer }\end{array}$ & 2018 & shp files & https://download.fgdl.org/pub/state/brownfields_areas_feb18.zip \\
\hline Hazardous waste sites & $\begin{array}{l}\text { Florida Geographic Data Library } \\
\text { Metadata Explorer }\end{array}$ & 2018 & shp files & https://download.fgdl.org/pub/state/chaz_jul18.zip \\
\hline
\end{tabular}


(continued)

Table 2. Indicators and Data Sources Used in SCAN360

\begin{tabular}{|c|c|c|c|c|}
\hline Indicator & Source & Year & Type & URL \\
\hline Correctional facilities & $\begin{array}{l}\text { Florida Geographic Data Library } \\
\text { Metadata Explorer }\end{array}$ & 2017 & shp files & https://download.fgdl.org/pub/state/gc_correctionalbnd_sep17.zip \\
\hline Fire stations & $\begin{array}{l}\text { Florida Geographic Data Library } \\
\text { Metadata Explorer }\end{array}$ & 2018 & shp files & https://download.fgdl.org/pub/state/gc_firestat_may18.zip \\
\hline Health care facilities & $\begin{array}{l}\text { Florida Geographic Data Library } \\
\text { Metadata Explorer }\end{array}$ & 2014 & shp files & https://download.fgdl.org/pub/state/gc_health_aug14.zip \\
\hline Parks & $\begin{array}{l}\text { Florida Geographic Data Library } \\
\text { Metadata Explorer }\end{array}$ & 2017 & shp files & https://download.fgdl.org/pub/state/gc_parks_sep17.zip \\
\hline Schools & $\begin{array}{l}\text { Florida Geographic Data Library } \\
\text { Metadata Explorer }\end{array}$ & 2017 & shp files & https://download.fgdl.org/pub/state/gc_schools_sep17.zip \\
\hline $\begin{array}{l}\text { Mobile home and RV } \\
\text { parks }\end{array}$ & $\begin{array}{l}\text { Florida Geographic Data Library } \\
\text { Metadata Explorer }\end{array}$ & 2018 & shp files & https://download.fgdl.org/pub/state/mhrv_mar18.zip \\
\hline Mammography centers & $\begin{array}{l}\text { US Food and Drug } \\
\text { Administration }\end{array}$ & 2017 & $\begin{array}{l}\text { Geocoded } \\
\text { addresses }\end{array}$ & $\begin{array}{l}\text { https://www.fda.gov/radiation-emittingproducts/ } \\
\text { mammographyqualitystandardsactandprogram/consumerinformation/ } \\
\text { ucm113962.htm }\end{array}$ \\
\hline $\begin{array}{l}\text { Special Supplemental } \\
\text { Nutrition Program for } \\
\text { Women, Infants, and } \\
\text { Children centers }\end{array}$ & $\begin{array}{l}\text { Special Supplemental Nutrition } \\
\text { Program for Women, Infants, } \\
\text { and Children }\end{array}$ & 2018 & $\begin{array}{l}\text { Geocoded } \\
\text { addresses }\end{array}$ & http://www.wicprograms.org/state/florida \\
\hline Free clinics & FreeClinics.com & 2018 & $\begin{array}{l}\text { Geocoded } \\
\text { addresses }\end{array}$ & https://www.freeclinics.com/co/fl \\
\hline HIV testing sites & Florida Department of Health & 2018 & $\begin{array}{l}\text { Geocoded } \\
\text { addresses }\end{array}$ & https://flhiv.doh.state.fl.us/ClinicSearch/textsearch.aspx?county=true \\
\hline $\begin{array}{l}\text { Pre-exposure prophylaxis } \\
\text { (PrEP) sites }\end{array}$ & Florida Department of Health & 2018 & $\begin{array}{l}\text { Geocoded } \\
\text { addresses }\end{array}$ & https://flhiv.doh.state.fl.us/ClinicSearch/textsearch.aspx?area=true \\
\hline $\begin{array}{l}\text { Sylvester Comprehensive } \\
\text { Cancer Center satellite } \\
\text { sites }\end{array}$ & $\begin{array}{l}\text { Sylvester Comprehensive } \\
\text { Cancer Center }\end{array}$ & 2018 & $\begin{array}{l}\text { Geocoded } \\
\text { addresses }\end{array}$ & $\begin{array}{l}\text { https://umiamihealth.org/sylvester-comprehensive-cancer-center/ } \\
\text { locations?category=all\&currentaddress=\&distance }=10\end{array}$ \\
\hline Academic cancer centers & $\begin{array}{l}\text { Florida Academic Cancer } \\
\text { Center Alliance }\end{array}$ & 2018 & $\begin{array}{l}\text { Geocoded } \\
\text { addresses }\end{array}$ & http://floridacancerresearch.org \\
\hline $\begin{array}{l}\text { Department of } \\
\text { Community Service } \\
\text { health fairs }\end{array}$ & $\begin{array}{l}\text { University of Miami Miller } \\
\text { School of Medicine, } \\
\text { Department of Community } \\
\text { Service }\end{array}$ & 2018 & $\begin{array}{l}\text { Geocoded } \\
\text { addresses }\end{array}$ & https://umdocs.mededu.miami.edu/projects \\
\hline Tobacco retailers & $\begin{array}{l}\text { Florida Department of } \\
\text { Business and Professional } \\
\text { Regulation }\end{array}$ & 2018 & $\begin{array}{l}\text { Geocoded } \\
\text { addresses }\end{array}$ & https://www.myfloridalicense.com/w|11.asp?mode $=1 \& S I D=\& b r d=\&$ typ $=$ \\
\hline
\end{tabular}

The opinions expressed by authors contributing to this journal do not necessarily reflect the opinions of the U.S. Department of Health and Human Services, the Public Health Service, the Centers for Disease Control and Prevention, or the authors' affiliated institutions. 